DOCTRINA

\title{
El interés público y la concesión minera en la Constitución. Aportes para su comprensión desde una perspectiva ambiental
}

\author{
The public interest and mining concessions in the constitution. \\ A contribution to its comprehension from an environmental perspective
}

\section{Liliana Galdámez Zelada (iD \\ Universidad de Chile}

\begin{abstract}
RESUMEN La Constitución chilena de 1980 afirma que el titular de una concesión minera debe desarrollar la actividad necesaria para satisfacer el interés público que justifica su otorgamiento. Este trabajo propone el desarrollo de dimensiones ambientales para la noción de interés público en la minería. La noción de interés público ha sido poco estudiada por la doctrina nacional y tiene incipiente desarrollo en la jurisprudencia, su comprensión ha sido restrictiva y se lo ha asociado en la práctica con dimensiones fiscales y económicas. Se analizará su significado ambiental a partir del derecho y jurisprudencia comparada, buscando aportar bases para una comprensión ambiental en la minería y en los criterios para la actuación de los jueces.
\end{abstract}

PALABRAS CLAVE Minería e interés público, nuevas dimensiones del interés público, acciones medioambientales de interés público, interés público global medioambiental.

ABSTRACT The 1980 Constitution states that anybody entitled with a mining concession 'must develop the activity needed to satisfy the public interest that justifies its awarding. This work proposes the development of environmental dimensions for the public interest notion in mining. The public interest concept has been scantly studied by the national doctrine and has incipient development in the jurisprudence, with a restrictive comprehension that has associated it with fiscal and economic dimensions. Its environmental meaning will be analyzed using comparative law and jurisprudence, seeking to contribute bases for the environmental grasping of the public interest in mining and criteria for judges' proceeding.

KEYWORDS Mining and public interest, new dimensions of the public interest, environmental public interest actions, global environmental public interest. 


\section{Introducción}

Las constituciones no hacen a los países, pero moldean una cierta comprensión y sentido de sociedad, del desarrollo, de los derechos, del poder. En Chile estas definiciones no han estado asociadas a procesos constituyentes participativos, por el contrario: «Todos los proyectos constitucionales han sido elaborados y discutidos por pequeños grupos asociados al poder de turno que han funcionado 'a puertas cerradas', con prescindencia absoluta de participación de la ciudadanía... sin la realización de un verdadero debate nacional» (Grez Toso, 2017: 32).

La Constitución de 1980 en cierta forma ha producido un país, una forma de sociedad basada en un fuerte acento en lo económico, que proclama el rol subsidiario del Estado, con énfasis en el reconocimiento y protección de derechos individuales, y que define como objetivo del Estado propender al bien común mientras «protege los cuerpos intermedios». Palabras como solidaridad apenas aparecen. Estos valores, principios y prioridades constitucionales inciden, cómo no, en la minería, que se aborda en la Constitución a partir del derecho de propiedad, sin referencias a los resguardos ambientales que esa actividad implica ni a su sostenibilidad. Las referencias ambientales que la Constitución contiene son genéricas, se configuran a través del derecho fundamental individual a vivir en un medio ambiente libre de contaminación como derecho autónomo y no como principio rector.

El mensaje que contiene la Constitución en el ámbito de la minería reproduce la comprensión y el desarrollo histórico de la minería en Chile:

La importancia de historiar este proceso degradativo radica en la centralidad que tiene hasta el día de hoy la industria del cobre en nuestro país, cuyo modelo de desarrollo no ha variado mucho desde sus orígenes hasta el día de hoy. La pregunta clave, en este sentido, es qué tan sustentable es y ha sido la industria del cobre en Chile (Folchi, 2001: 171).

Así la Constitución de 1980 se inspira en una idea desarrollista y expansiva de la actividad minera sin otras referencias que no sean a la propiedad estatal minera y su explotación a través de concesiones. Este y otros factores han incidido en la restrictiva interpretación de la noción de interés público. La Constitución contiene la siguiente frase, a propósito de la propiedad minera: «La concesión minera obliga al dueño a desarrollar la actividad necesaria para satisfacer el interés público que justifica su otorgamiento» (artículo 19 número 24 ). ¿En qué consiste ese interés público que debe satisfacer el titular de una concesión minera? No se trata de una cuestión estrictamente teórica: esta pregunta se plantea en un contexto de preocupación y creciente conflictividad ambiental.

El modelo de crecimiento económico chileno y de otras economías de la región se ha basado principalmente en la explotación de recursos naturales. En el caso chileno, 
del cobre (OCDE y Cepal, 2016). Y si bien la Constitución de 1980 aborda prematuramente la cuestión ambiental, lo hace desde una significación idealizada y clásica, que valora la preservación de la naturaleza (Galdámez Zelada y Millaleo Hernández, 2020: 54), y que consagra un derecho fundamental y que autoriza la restricción legislativa de otros derechos. En la parte primera, de las Bases de la Institucionalidad, la Constitución carece de principios rectores para la explotación de los recursos naturales. Sin embargo, en el capítulo de los derechos, artículo 19 número 24, a propósito del régimen de propiedad minera, el constituyente introdujo una obligación para el titular de la concesión minera, que debe satisfacer el interés público que justifica su otorgamiento. Esta norma ha sido muy poco examinada y su interpretación hasta ahora ha sido muy restrictiva.

En Chile el interés público que debe satisfacer el titular de una concesión minera se ha comprendido como interés fiscal (por el pago de patentes) o interés económico (por el efectivo desarrollo de la actividad de exploración o explotación). Son los únicos significados que la doctrina ha analizado y el debate se limita a definir cuál satisface tal interés público.

Por otra parte, si bien la Constitución aborda dimensiones ambientales, en la práctica han sido opacadas por el crecimiento desproporcionado de los derechos individuales de contenido económico, derecho de propiedad (artículo 19 número 24), a la propiedad (artículo 19 número 23), la libertad de empresa (artículo 19 número 21), de aprovechamiento de aguas (artículo 19 número 24). Todos protegidos por la acción de protección (artículo 20) reforzada por el amparo económico (Ley 18.971) ${ }^{1}$ para la protección de la libertad de empresa.

Como ya señalé, refuerza también los contenidos económicos individuales de la Constitución la lógica del Estado subsidiario (cf. Galdámez Zelada, 2017: 198), que se introduce como principio rector:

de naturaleza organizacional y política y jurídica que aplica a la distribución de competencias entre el Estado y los grupos intermedios y que se resuelve en la afirmación esencial de que el Estado no debe intervenir en las actividades que son de competencia de los grupos intermedios, a menos que por inexistencia o deficiencia de la acción de tales grupos y en subsidio de la misma el Estado deba intervenir (Tapia Valdés, 2003: 99).

Matizando los contenidos antes descritos, la Constitución incluye también la función social de la propiedad, que se concibe en los siguientes términos: «comprende cuanto exijan los intereses generales de la Nación, la seguridad nacional, la utilidad y la salubridad públicas y la conservación del patrimonio ambiental» (artículo 19 número 24). Cabe señalar que esta disposición no ha tenido un impacto que permita

1. Sobre esta materia, véase Galdámez y Millaleo (2020). 
el desarrollo de otras dimensiones, más allá de las fiscales y económicas del interés público, y a mayor abundamiento, como señala Ruiz Tagle, existen dilemas y contradicciones en el estatuto jurídico de la propiedad, derivados, entre otras cuestiones, de su regulación en el marco de a Constitución y en el Código Civil, esto es, en cuanto su régimen público y privado. Estos dilemas se reproducen en la jurisprudencia y en la doctrina (Ruiz Tagle, 2018: 228). No existen desarrollos relevantes para la función social de la propiedad del titular de una concesión minera, particularmente en lo que se refiere a la protección del patrimonio ambiental.

En este contexto, propongo analizar la forma en que se ha dotado de contenido ambiental al interés público en el derecho comparado e internacional, y reflexionar acerca de su limitada interpretación en el ordenamiento chileno.

El interés público es un concepto jurídico indeterminado que posee significados diversos. Los debates sobre el sentido y alcance del interés público no son nuevos. En las discusiones de la década del sesenta, el interés público parecía más una línea que separaba lo público de lo privado que un concepto con contenido propio.

En 1962, «los miembros de la sociedad estadounidense de Filosofía y Política Legal» (Friedrich, 1962: 9) publicaron The public interest, que reúne un conjunto de trabajos sobre el concepto del interés público. Los resultados son tan diversos y variados en cuando puntos de vista y metodología, que finalmente no llegan a un acuerdo «sobre el alcance en la aplicación del concepto», que van desde su rechazo por servir a intereses políticos, hasta su valoración por su aporte a la comprensión de lo público (Friedrich, 1962: 9). Esta incertidumbre es un lugar común en los trabajos que analizan el interés público desde un punto de vista teórico. Es a finales del siglo XX que el interés público va a adquirir un nuevo contenido: el medio ambiente.

Este trabajo se organiza en dos partes. En la primera analizaré el interés público y la minería en la Constitución chilena y en el derecho comparado, los criterios del Tribunal Constitucional, la relación entre interés público y minería, doctrina y desarrollo normativo en Chile, y entre minería y conflictividad socioambiental. En la segunda parte, analizaré la noción de interés público en la doctrina nacional; las dimensiones ambientales del interés público a través del estudio de las acciones de litigio por interés público medioambiental y el interés público global ambiental. Terminaré con un apartado de conclusiones. Operará como eje articulador del trabajo el análisis del uso de la noción interés público en el derecho constitucional comparado, en el derecho internacional y en la jurisprudencia, especialmente su vínculo con lo ambiental. 


\section{Primera parte}

El interés público y la minería en la Constitución chilena y el derecho comparado

Desde una perspectiva Constitucional:

Häberle sostiene que el interés público debe analizarse como parte del orden constitucional y como material normativo dentro de una «teoría constitucional democrática». En este sentido mantiene la importancia de una interpretación constitucional como concretización del interés público (López Calera, 2010: 131).

Más próximo a un principio que a una regla, el interés público aparece como una categoría dúctil. Según Zagrebelsky, mientras a las reglas se las obedece, a los principios se presta adhesión, y agrega que una de las características de los principios es que poseen una autónoma razón de ser frente a la realidad. De esta forma, los principios al entrar en contacto con la realidad se vivifican, se adaptan, recrean nuevas dimensiones de esa realidad (Zagrebelsky, 2011: 110).

Desde la idea de un constitucionalismo transformador, se trata de una noción además vinculada con un rasgo que von Bogdandy (2015: 16) identifica como común en la región latinoamericana, la idea de una justicia que se desarrolla en base a principios.

El Diccionario Panhispánico del Español Jurídico define interés público como un «conjunto de aspiraciones surgidas de las necesidades colectivas de los miembros de una comunidad y protegidas mediante la intervención directa y permanente del Estado». ${ }^{2}$ Se trata de un concepto que, incluso en su indeterminación, contiene algunos elementos centrales estables: el interés público se relaciona con la colectividad, con aquello que le es común y su protección se concreta a través de la intervención directa del Estado.

La doctrina nacional apenas ha explorado el contenido y significado del interés público en la minería. Se trata de una cláusula que no ha desplegado su fuerza normativa o lo ha hecho en un sentido demasiado limitado, como señalé. En el derecho constitucional comparado, especialmente latinoamericano, el interés público se consagra en constituciones históricas como la de México de 1917 y en el nuevo constitucionalismo latinoamericano (Salazar Ugarte, 2013: 356), donde se le menciona a propósito de los recursos naturales, de la mano del llamado «nacionalismo de los recursos» (Espinoza, 2007: 21) para justificar su dominio para el Estado, y para promover su uso sostenible.

La Constitución Mexicana de $1917^{3}$ menciona al interés público en su texto original y también lo incorpora a través de reformas, como la del artículo 25, donde el

2. Diccionario Panhispánico del Español Jurídico, entrada disponible https://bit.ly/3n59rjh.

3. Otras referencias al interés público en la Constitución Política de los Estados Unidos Mexicanos: artículo 2 VIII; artículo 6 I; artículo 25; artículo 27 XVIII. 
interés público se relaciona con economía, productividad y sustentabilidad de las empresas (de sectores sociales y privados), cuya actividad debe sujetarse «a las modalidades que dicte el interés público y al uso, en beneficio general, de los recursos productivos, cuidando su conservación y el medio ambiente».

Las constituciones de Bolivia, Ecuador y Venezuela, parte del nuevo constitucionalismo latinoamericano, ${ }^{4}$ incluyen el interés público en ámbitos estratégicos de la economía y a propósito de la explotación de recursos naturales. En Bolivia, ${ }^{5}$ el artículo 346 de la Constitución señala:

El patrimonio natural es de interés público y de carácter estratégico para el desarrollo sustentable del país. Su conservación y aprovechamiento para beneficio de la población será responsabilidad y atribución exclusiva del Estado, y no comprometerá la soberanía sobre los recursos naturales...».

Y agrega en el artículo 348: «Los recursos naturales son de carácter estratégico y de interés público para el desarrollo del país».

En Ecuador, la Constitución en el artículo $14^{6}$ dice:

Se reconoce el derecho de la población a vivir en un ambiente sano y ecológicamente equilibrado, que garantice la sostenibilidad y el buen vivir, sumak kawsay. Se declara de interés público la preservación del ambiente, la conservación de los ecosistemas, la biodiversidad y la integridad del patrimonio genético del país, la prevención del daño ambiental y la recuperación de los espacios naturales degradados.

En Venezuela, la Constitución en el artículo 302 señala:

El Estado se reserva, mediante la ley orgánica respectiva, y por razones de conveniencia nacional, la actividad petrolera y otras industrias, explotaciones, servicios y bienes de interés público y de carácter estratégico.

La referencia al interés público en el constitucionalismo comparado no ha dado lugar a polémicas y ha sido poco analizado, mientras que la invocación del sumak kawsay ha sido más debatido. En este sentido afirma Gargarella:

Se puede valorar la intención de incorporar «principios interpretativos» nuevos, diferentes a los tradicionales [...]; sin embargo, es difícil no preguntarse cómo

4. Según Gargarella (2018: 110), a partir de la aprobación de las Constituciones de Colombia (1991), Venezuela (1999), Ecuador (2008) y Bolivia (2009), se suele hablar de la existencia de un «nuevo constitucionalismo latinoamericano».

5. Otras referencias al interés público la Constitución Política del Bolivia están en: artículo 158.I. 12; artículo 300 I, 25; artículo 302.I. 22.; artículo 346; artículo 348. I, II; artículo 392. II.

6. Otras referencias al interés público en la Constitución de la República del Ecuador están en los artículos 14, 28, 400 y 409. 
entender tales principios cuando la Constitución no reniega de otros principios e instituciones contrarias (i. e., vinculadas con tradicionales derechos de propiedad) (Gargarella, 2018: 125).

La coincidente relación que estas constituciones contemplan entre recursos naturales e interés público da cuenta de una dimensión clásica, por un lado, y una novedosa en su interpretación, por otro. A partir de la primera, el interés público opera como fundamento del dominio estatal de los recursos naturales; a partir de la segunda, se promueve la explotación sostenible de los recursos naturales.

\section{La dimensión ambiental del interés público en la jurisprudencia del Tribunal Constitucional}

Para avanzar, y con el objeto de demostrar la importancia que tiene explorar en el significado de este concepto jurídico indeterminado, se debe tener presente el trabajo interpretativo que el Tribunal Constitucional ha desarrollado para dotar de contenido a otras cláusulas abiertas de la Constitución.

La jurisdicción constitucional chilena ha prestado especial atención a la dignidad de la persona humana: la idea del bien común, el Estado al servicio de la persona humana (todas referencias contenidas en el artículo 1 de la Constitución). A partir de su interpretación se han impulsado matices y énfasis en la protección de derechos sociales, como la salud y la educación. Así, por ejemplo, ha dicho el Tribunal Constitucional a propósito del catálogo de derechos:

Que el contenido del artículo 19 de la Carta Fundamental, conjuntamente con sus artículos 1, 4 y $5[\ldots]$ configuran principios y valores básicos de fuerza obligatoria que impregnan toda la Constitución de una finalidad humanista que se irradia en la primacía que asignan sus disposiciones a la persona humana, su dignidad y libertad natural; y al respeto, promoción y protección de los derechos esenciales que emanan de la naturaleza humana, que se imponen como limitación del ejercicio de la soberanía y como deber de los órganos del Estado... Que estos principios y valores no configuran meras declaraciones programáticas, sino que constituyen mandatos expresos para gobernantes y gobernados (Sentencia rol 2747, del 25 de agosto de 2015).

La atención que el Tribunal Constitucional chileno ha prestado a estas cuestiones, por su conformación como valores y principios del orden constitucional (Alexy, 2004), ha sido evolutiva y ha favorecido una nueva comprensión de algunos derechos como la salud, matizando su sentido y alcance para ampliarlo, aunque aún de manera insuficiente si se tiene en cuenta la condena a Chile por la Corte IDH en el caso Poblete Vilches. ${ }^{\text {? }}$

7. En este caso, la Corte IDH condenó al Estado chileno por afectación del derecho a la salud de una 
Contrariamente a la tendencia apreciada en la protección del derecho a la salud, en su jurisprudencia ambiental, el Tribunal Constitucional transita por etapas que van desde la escasa comprensión de las dimensiones ambientales de la Constitución (roles 146 de 1992 y 185 de 1994), hacia una etapa pendular donde a veces se considera la protección del medio ambiente como valor o derecho fundamental, mientras que en otros casos se refuerza la protección de los derechos económicos (roles 2299 de 2012 y 2644 de 2015 (Galdámez Zelada, 2020).

Dicho lo anterior, es en la sentencia rol 2684 de 2015, donde el Tribunal Constitucional se refiere a una nueva dimensión del interés público:

Dicho interés público ha de estar al servicio de la persona humana y debe promover el bien común. [...] Asimismo, los órganos del Estado no podrían sino justificar el otorgamiento de una concesión minera en plena armonía con todos los contenidos del artículo 19, los que, entre otros, incluyen el deber de velar por el respeto del derecho a vivir en un medio ambiente libre de contaminación. De todo lo anterior puede deducirse que el interés público que justifica el otorgamiento de la concesión minera no tiene un carácter unidimensional y que de modo ineludible debe integrar distintos principios y valores constitucionales.

El razonamiento que se contiene en esta decisión ha sido un antecedente importante para el estudio del interés público que propongo.

\section{Interés público y minería: doctrina y desarrollo normativo en Chile}

La actividad minera representa para Chile el $52 \%$ de las exportaciones. El $48 \%$ se relaciona con la explotación de cobre. Según la OCDE: «La economía [chilena] sigue siendo muy dependiente del cobre [...] al tiempo que los precios de las materias primas y las enfermedades que han afectado al salmón han puesto en entredicho los motores tradicionales del crecimiento» (OCDE, 2018: 24).

La minería es estratégica para el país. Chile conserva el $29 \%$ de las reservas de cobre mundial. Es el mayor productor y generó el $37 \%$ de la producción mundial de cobre (OCDE, 2018: 23). La importancia del cobre también ha sido problematizada. Se ha hablado de la maldición de los recursos naturales, aunque para Meller, no existe suficiente evidencia que demuestre que los países abundantes en recursos naturales estén condenados a bajas tasas de crecimiento (2003: 22). Radomiro Tomic señalaba en 1986, a propósito de la política del cobre, que la economía mundial y el desarrollo de la industrialización se sostienen en cuatro materias primas imprescindibles: hierro, madera, petróleo y cobre (Tomic, 1986: 26).

persona mayor, que falleció en el contexto de una mala y deficiente atención médica, además de la vulneración de otros derechos. Corte Interamericana de Derechos Humanos, caso Poblete Vilches y otros vs. Chile, 8 de marzo de 2018. 
Desde el punto de vista jurídico, la figura de la concesión minera es imprescindible para comprender la forma en que se desarrolla la actividad en Chile, estatuto cuyas bases esenciales son establecidas en la Constitución y en la Ley 18.097. El marco jurídico regulador de la minería se construye desde la forma de una concesión minera plena, que implicaba, según de José Piñera comentado por Tomic: «no dependencia del poder político, por ello su concesión se establece por el poder judicial, reforzando el magen de la iniciativa privada oponible al Estado; un derecho amplio, ajeno a controles financieros, ni a obligaciones impuestas por el ejecutivo; de duración indefinida, su existencia solo depende del pago de la patente; protegida por el derecho de propiedad. En consecuencia, «el titular puede libremente usar, gozar y disponer de la concesión a su entera voluntad, vale decir, vender, hipotecar, dar en garantía, transmitir hereditariamente, etc., y, por otra parte, que no puede ser privado de ella, sino por expropiación [que] origina indemnización completa» (Tomic, 1986: 49).

Como dijimos, las dimensiones que se han desarrollado para la comprensión del interés público en la minería, tanto en la doctrina como en las normas, son de contenido fiscal y económico, como analizaremos en los siguientes apartados. Alejandro Vergara Blanco es quien más se ha ocupado de analizar el sentido y alcance de la referencia al interés público en la minería. Para él, el sentido del interés público en la Constitución no es otro que el de obligar al titular de una concesión minera a desarrollar la actividad (explorar, explotar) que justifica su otorgamiento. Esto es, desarrolla una valoración del significado económico del interés público. Vergara afirma que no es poco frecuente que se concedan permisos de explotación o exploración y que luego el titular no desarrolle la actividad para buscar y extraer el mineral (Vergara Blanco, 1989: 44).

Vergara Blanco es crítico con la Ley Orgánica sobre Concesiones Mineras (Ley 18.097) porque para el legislador el interés público se satisface (artículo 12) a través del pago de una patente (Vergara Blanco, 1989: 44), mientras que para él es la actividad de exploración o explotación lo que concreta ese interés público que el concesionario debe satisfacer.

Desde esta perspectiva, en definitiva, el interés público se concreta porque el titular de la concesión desarrolla la actividad a la que fue autorizado (interés económico), o porque paga una patente en razón del derecho de exploración y/o explotación (interés fiscal). También Zúñiga Urbina (2005) trata indirectamente este tema, pero su tesis va más en la dirección del nacionalismo de los recursos y, de la misma manera que Vergara Blanco, Zúñiga deja entrever que el interés público se satisface con el desarrollo de la actividad de exploración y/o explotación. Por otra parte, el régimen de amparo de la propiedad minera, según Claussen (1988), se ha comprendido en dos campos. Uno relacionado con el sistema de amparo del trabajo y el otro vinculado al pago de una patente. Para el caso de Chile, la implementación de estos sistemas depende el interés jurídico que el legislador pretende asegurar. Cuando se trata de 
ofrecer mayor certeza jurídica al inversionista, el legislador optará por un régimen de amparo basado en el pago de patente. Es la Ley 18.097 Orgánica Constitucional la que, en definitiva, delimita el interés jurídico que busca proteger, dado que la Constitución en su artículo 19 número 24 lo delega en el legislador. Claramente la Ley 18.097 opta por proteger los intereses jurídicos del inversionista al establecer en el artículo 12 un pago de patente anual (Claussen, 1988: 175). Tal opción no se ajustaría al mandato constitucional, coincidiendo Claussen en este punto con Vergara Blanco.

El interés fiscal al que me he referido como dimensión del interés público, sin embargo, no se concreta en un impuesto especial para la actividad minera (royalty). Así ocurre en países como Marruecos, el Congo o Namibia (Folchi, 2009: 80). Según un estudio encargado por el Consejo Minero, además, «desde el punto de vista de los impuestos corporativos, Chile se sitúa entre aquellos países con menor carga tributaria» (EY, 2018: 16).

Estos y otros antecedentes han llevado a la presentación de un proyecto de ley para establecer el royalty minero por la explotación de cobre y litio (Boletín 12093o8). Este proyecto se encuentra a esta fecha en segundo trámite constitucional en el Senado. El proyecto de ley no invoca el interés público, pero se puede entender como un interés implícito. Define a este impuesto como «un derecho que el Estado soberano cobra al concesionario por la explotación de sus riquezas naturales, el cual es aplicado en gran parte de los países desarrollados, abundantes en recursos naturales» (Boletín 12093-08). El proyecto establece un impuesto

equivalente al $3 \%$ del valor nominal de los minerales extraídos. Dicha compensación deberá destinarse a obras de desarrollo en las comunas en donde se encuentren los yacimientos respectivos de donde se extraiga el mineral, que permitan mitigar los efectos ambientales que produzca la actividad minera.

La propuesta fue ingresada a la Cámara de Diputados en 2018, no es posible anticipar cómo concluirá, no obstante, ha ido sorteando las distintas etapas en ambas cámaras del Congreso. Este impuesto en discusión reafirma la dimensión fiscal del interés público. Dicho esto, también es de reconocer que se relaciona con su dimensión ambiental, aunque en un campo muy acotado, dado que se comprende como una forma de mitigación, y no refiere al principio preventivo ni al precautorio.

Como acabamos de ver, tampoco el interés económico y fiscal ha tenido un desarrollo fuerte en el ordenamiento chileno. Recién en 2018 comienza a avanzar la idea de un royalty, aunque en mi opinión, lo hace desde una perspectiva muy limitada.

Desde el punto de vista legislativo, el Código de Minería de 1983 no contiene referencias ni desarrollos sobre el interés público, aunque cita el interés nacional (artículo 22.1, 22), el interés de la defensa nacional (artículo 17.6), el interés económico (artículo 142), el interés de la sociedad (artículo 188) y el interés histórico o científico (artículo 17.7). A su vez, la Ley Orgánica Constitucional sobre Concesiones Mineras 
solo se refiere al interés público en el artículo 7 , cuando señala que la facultad de catar y cavar debe ejercerse de conformidad a la ley «y estará sujeta a las a fines de interés público», sin más referencias o desarrollos.

Por su parte, la Ley 19.300 sobre Bases del Medio Ambiente no menciona al interés público, aunque se refiere en cuatro normas a la minería (artículos 10, 20, 71 y 86). De ellas solo el artículo 10 nos interesa, ya que la menciona entre las actividades «susceptibles de causar impacto ambiental, en cualesquiera de sus fases, [y] que deberán someterse al sistema de evaluación de impacto ambiental...» cuando se trata de proyectos de desarrollo minero (letra i, artículo 10 Ley 19.300). Bajo esta fórmula, al estatuto de la concesión minera se superpone y agrega el régimen jurídico ambiental, contenido en la Ley 19.300. Sin embargo, el estatuto ambiental tampoco ha desarrollado de manera consistente la noción de interés público en sus dimensiones ambientales.

Según lo analizado, en Chile la actividad minera no ha sido tratada desde una perspectiva constitucional, salvo en lo referente a su régimen de propiedad, mientras que otras constituciones de la región contienen directrices sobre el desarrollo de la minería y la sostenibilidad, en las que el interés público se configura como principio rector. Para el caso de Chile, el interés público que obliga al titular de la concesión minera ha sido comprendido en sentido fiscal y económico, la idea de que el titular de la concesión minera desarrolle sus actividades tributando un interés público ambiental ha estado ausente de los desarrollos del interés público.

\section{Minería y conflictividad socioambiental}

Precisamente por la importancia estratégica del cobre para Chile, es que Tomic afirmaba que, entre los errores más importantes posteriores a 1973, se encuentra haber aplicado a la explotación del cobre los mismos criterios de la Escuela de Chicago. ¿Dónde se expresan estos criterios? En lo que ya hemos señalado, privatización, subsidiariedad, división internacional del trabajo, «según las ventajas comparativas» $y$ «el mercado $-\mathrm{y}$ no acuerdos de productores de ninguna índole- como supremo regulador del precio internacional del cobre» (Tomic, 1986: 48).

Otro error fundamental, señalado por Tomic, y que se relaciona con la conflictividad ambiental, proviene de la forma en que la política del cobre comprendió, erróneamente, que existía una amenaza latente por el progreso tecnológico y científico, semejante a lo ocurrido en el pasado con el salitre, que dejaría al cobre obsoleto en el mercado de metales. Frente a esta equivocada amenaza, ante la falta de capacidades técnicas y científicas del país, debían generarse condiciones que permitieran

la mayor extracción y exportación de cobre en el menor tiempo posible [...] El gobierno estaba dispuesto a dar a los inversionistas extranjeros interesados en producir y exportar cobre desde Chile, todas las garantías necesarias asignándoles rango constitucional e incluyendo «el riesgo jurídico» (Tomic, 1986: 48). 
Estos criterios fueron incorporados en la Ley Minera 18.097, que creó la figura de la «concesión minera plena» (Tomic, 1986: 50; Folchi, 2009: 80 ). La conflictividad socioambiental condensa las tensiones que la exploración y explotación minera producen en las comunidades y la ausencia de una operacionalización ambiental de un interés público que la Constitución menciona.

El mapa de conflictos socioambientales elaborado por el Instituto Nacional de Derechos Humanos en 2018 identifica 117 conflictos socioambientales. De ellos, 63 están activos, 30 latentes y 24 están cerrados. Un análisis del informe muestra que, de esos conflictos, el $38 \%$ se relaciona con energía; el $28 \%$ con la minería; el $9 \%$ saneamiento ambiental, mientras que el $25 \%$ responde a otros sectores. Según el informe, entre los derechos afectados se encuentran el derecho a la participación y consulta indígena, el derecho a la participación y el derecho al territorio y los recursos naturales. Todos los conflictos socioambientales poseen una dimensión ambiental y territorial. ${ }^{8}$ Por su parte, la OCDE en su Informe 2016 afirma:

A raíz de la creciente actividad económica, de una mayor extracción y uso de recursos naturales, y del desarrollo y la expansión de la infraestructura, se intensifican las presiones que sufre la variada diversidad biológica de Chile. La profunda desigualdad en materia de ingresos exacerba los conflictos ambientales y alimenta la desconfianza. Los objetivos relacionados con la diversidad biológica se están integrando progresivamente en otras áreas de política, como la agricultura, la silvicultura y la minería, pero aún no se han materializado resultados tangibles» (OCDE y Cepal, 2016: 2).

Asimismo, el Informe OCDE 2018 advierte sobre los riesgos de contaminación de suelos y agua producto de la actividad minera y agrícola que no son evaluados de forma permanente (OCDE, 2018: 60).

En el mismo sentido, el Informe del Centro de Análisis de Políticas Públicas de la Universidad de Chile, agrega:

La modalidad de desarrollo adoptada por el país privilegió por sobre cualquier otra dimensión, el crecimiento económico [...] El incremento del poder adquisitivo de la población, amén del mejoramiento de las condiciones de vida, ha generado fuertes presiones sobre el medio ambiente (Centro de Análisis de Políticas Públicas, 2015: 24).

8. Según INDH, un conflicto socioambiental es: «disputas entre diversos actores - personas naturales, organizaciones, empresas públicas y privadas, y el Estado-, manifestadas públicamente y que expresan divergencias de opiniones, posiciones, intereses y planteamientos de demandas por la afectación (o potencial afectación) de derechos humanos, derivada del acceso y uso de los recursos naturales, así como por los impactos ambientales de las actividades económicas». Véase INDH, «INDH presenta Mapa de conflictos socioambientales en Chile y anuncia recurso de protección en favor de habitantes de Quintero», disponible en https://bit.ly/32b33yY. 
Mientras que el segundo informe de esta serie, y que cubre el año 2018, afirma que el incremento y expansión de la actividad minera y la baja ley del cobre que se explota han incrementado los costos de extracción y transporte, mientras que por otra parte subsisten graves problemas por pasivo ambiental producto de relaves y minas cerradas sin ser recuperados, y porque las mediana y pequeña industria utiliza formas de producción con impacto ambiental y las disputas por el agua, especialmente en el norte del país (Centro de Análisis de Políticas Públicas, 2018: 20).

El estatuto constitucional de la minería en Chile se ha limitado, como se ha visto, a reservar la propiedad de los recursos para el Estado y delegar su explotación por los privados a través de la concesión minera, mientras que el interés público (que está obligado a satisfacer) se ha comprendido en un sentido fiscal y económico.

En la segunda parte de este trabajo propongo examinar los desarrollos del interés público en la doctrina para posteriormente profundizar en sus dimensiones ambientales.

\section{Segunda parte}

La noción del interés público en la doctrina nacional

El interés público se encuentra en el ámbito de lo público y no en lo privado. Mientras el segundo ha experimentado un proceso de expansión, bajo la Constitución del 1980 lo público se ha desdibujado.

Desde el punto de vista teórico, al uso del interés público en los discursos, en las normas y en la jurisprudencia se le atribuye de manera intuitiva un sentido tan natural y obvio como indeterminado cuando uno se detiene en su significado. Se usa discursivamente pero nunca se define qué es el interés público.

La doctrina ha analizado el interés público, desde dos perspectivas. Una desarrolla una aproximación teórica al concepto de interés público, su definición, contenido y significado, y la otra analiza su interacción con un interés concreto, como el medio ambiental o global (Cornago, 2015; Voigt, 2018), como antecedente del derecho regulatorio (Feintuck, 2004), por su rol en la delimitación de derechos fundamentales, y según ubicación normativa o discursiva (Lewis, 2006), entre otras (Douglass, 1980; Guess, 2003; Gruning, 2009; Roxbee Cox, 1973; Feintuck, 2004; Croley, 2004; Elliot, Varuhas y Wilson, 2018). Cuando se estudia en esta segunda perspectiva, los autores no suelen responder a la pregunta sobre qué es el interés público.

Por su parte, en la doctrina nacional el interés público ha sido analizado en base a los siguientes criterios. 
Como criterio delimitador de los derechos fundamentales. ${ }^{9} \mathrm{El}$ interés público contribuye a definir contenido, límites y criterios para resolver colisiones o conflictos entre derechos fundamentales (Peña y Rosales, 2010: 483). Así, como técnica para resolución de tensión entre derechos, como regla de ponderación y como test, su invocación permite definir:

entre el beneficio que reporta el dar a conocer la información solicitada versus el daño que su divulgación generaría [...] Se denomina test de interés público porque se asume que solo un interés público predominante justifica traspasar aquella barrera que impide revelar información que se encuentra protegida por los derechos fundamentales (Covarrubias, 2012a: 504).

Interés público justifica la ampliación del derecho regulatorio. ${ }^{10} \mathrm{El}$ interés público aparece como fundamento del derecho administrativo y regulatorio. Se puede afirmar que es «uno de los conceptos más fundamentales de toda teoría del Estado y del derecho, particularmente del derecho administrativo» (López Calera, 2010: 129). Según Peña Torres y Rosales Rigol (2010: 487), las tensiones generadas al interior de los sistemas sociales han hecho necesario el reconocimiento del rol regulatorio del Estado para corregir y neutralizar las externalidades de la falta de control del Estado sobre la economía.

Interés público como fundamento de obras públicas de gran envergadura. ${ }^{11}$ Por ejemplo, cuando en su cuenta pública 2019, el presidente Sebastián Piñera anuncia que el Ministerio de Obras Públicas declara de interés público la construcción de un tren para unir Valparaíso y Santiago. ${ }^{12}$

9. En la doctrina nacional, se encuentran, entre otros, los siguientes trabajos sobre interés público: Peña Torres y Rosales Rigol (2010), Covarrubias (2012a y 2012b), Lovera (2006) y Figueroa (2016). Peña Torres y Rosales Rigol (2010), identifican tres dimensiones del interés público: 1) el interés público como concepto delimitador del ejercicio de los derechos fundamentales; 2) el interés público como cláusula de habilitación para el ejercicio de potestades; 3 ) el interés público como criterio delimitador para resolver la colisión o conflicto entre derechos fundamentales.

10. Artículos 5 letra j), 14 letra j) y 61 número 12, de la Ley 15.840 Orgánica del Ministerio de Obras Públicas; artículos 4 número 2, 6 números 1, 2 y 3, 44 letra c), 69 número 1, 79 número 2, y 2 número 1 transitorio, del Reglamento del Ministerio de Obras Públicas.

11. Según Ministerio de Obras Públicas, «de acuerdo con la Ley de Concesiones y su Reglamento, cualquier persona natural o jurídica podrá postular ante el Ministerio, como iniciativa privada, la ejecución de obras públicas mediante el Sistema de Concesiones. En una primera etapa, llamada «etapa de presentación», la iniciativa privada es revisada, por el Ministerio de Obras Públicas y los organismos del Estado competentes, con el propósito de establecer si existe, en principio, Interés Público en el Proyecto presentado, o si en base a los análisis realizados, se estima que el Proyecto no es viable». Véase Dirección General de Concesiones, MOP, Iniciativas privadas, disponible en https://bit.ly/3pF4Aa7.

12. Cámara Aduanera, «Sebastián Piñera: MOP declara de interés público proyecto de tren rápido entre Santiago y Valparaíso», 3 de junio de 2019, disponible en https://bit.ly/3EoWvjK. 
Esas categorías obedecen a las líneas clásicas de investigación en torno al sentido y alcance del interés público. En los siguientes apartados analizaré las dimensiones ambientales el interés público.

\section{Las dimensiones ambientales del interés público}

El interés público ambiental no ha sido incorporado por vía interpretativa en la Constitución. Esto no es extraño y no es un fenómeno aislado, otros ámbitos de la vida comunitaria que antes no fueron de interés de la Constitución ahora lo son. Según Barnes:

El derecho administrativo podría informarle al derecho constitucional de lo que está ocurriendo en la regulación de la economía, para así enriquecer la Constitución económica, que deberá re-definir sus orientaciones, extrayendo valores de sus filones. El derecho constitucional le podría transmitir al derecho administrativo los valores que es necesario inocular en esos nuevos escenarios (2012: 55).

En materia ambiental la naturaleza colectiva de la afectación de derechos, los límites procedimentales para su protección jurisdiccional y la condición transnacional de los problemas ambientales han impulsado nuevas respuestas jurisdiccionales y convencionales coherentes con la existencia de un interés público ambiental. Tan importante ha sido esto que se promueven por vía convencional y jurisprudencial los derechos de acceso a la justicia ambiental (Cepal, 2018).

En los siguientes apartados analizaré dos perspectivas del interés público ambiental: la litigación por acciones de interés público ambiental y el interés público global ambiental, que busca hacer frente a los desafíos planetarios que Naciones Unidas y órganos internacionales alertan (cf. ONU Medio Ambiente, 2019).

\section{Acceso a la justicia y acciones de Litigación por interés público medioambiental}

Las acciones de interés público ambiental se reproducen y amplían a partir de la experiencia de los Estados Unidos y tienen creciente desarrollo en India, Sudáfrica, China y en nuestra región en Colombia y Argentina, entre otros países (Sabel, Simon y Mamberti, 2018). Los litigios ambientales por interés público se caracterizan por la afectación de derechos colectivos; por afectar vastos territorios y ecosistemas complejos; porque involucran tensiones con el derecho de propiedad y la libertad de empresa; también, porque suelen enfrentarse actores de desigual poder.

Como respuesta a las complejidades que se aprecian en los litigios ambientales, los jueces amplían por vía jurisprudencial criterios de legitimación activa; tipología y control de otros órganos para cumplimiento de sentencias; medidas de hacer novedosas y facilitan mecanismos de asistencia a grupos para comparecencia en litigios, para asegurar los derechos de acceso a la justicia ambiental. 
El acceso a la justicia ambiental no es solo una preocupación abordada por los jueces, esta preocupación coincide con las prioridades y compromisos que se discuten en el ámbito internacional. En este sentido, el acuerdo de Escazú, «Acuerdo Regional sobre el Acceso a la Información, la Participación Pública y el Acceso a la Justicia en Asuntos Ambientales en América Latina y el Caribe», adoptado en marzo de 2018 en cuya negociación participó Chile, aunque no en su firma, refuerza el acceso a la justicia considerando varias de las cuestiones que se han desarrollado por vía jurisprudencial. En el acuerdo de Escazú, el interés público es mencionado en los artículos 5.8 y 9 sobre acceso a la información ambiental y en el artículo 7 , sobre participación pública en los procesos de toma de decisiones ambientales. El reforzamiento del acceso a la justicia obedece al interés público presente en los litigios ambientales.

A modo de ejemplo, en el caso Urgenda (Urgenda Foundation v. State of the Netherlands), en la sentencia de 24 junio de 2015, la acción se entabla en la Corte distrital de La Haya para que persuada al Estado de Holanda para reducir drásticamente las emisiones de $\mathrm{CO}_{2}$. Esta reducción requiere, según la demandante, prevenir los peligros del cambio climático que puedan ocurrir en el futuro (Voigt y Makuch , 2018: 307).

Se trata de un claro litigio por interés público ambiental:

La organización Urgenda, actuando en representación de 886 particulares y propia, demandó al Ministerio de Infraestructuras y Medio Ambiente [...]. En el núcleo de sus pretensiones estaba que el Tribunal ordenase al ejecutivo holandés que actuara para que en 2020 se reduzca la cantidad de emisiones de $\mathrm{CO}_{2}$ respecto a 1990 en un 40\% o, al menos, en un 25\% (Rodríguez García, 2016: 7).

La demanda fue acogida y el Tribunal de Distrito de La Haya declaró, «al Gobierno de los Países Bajos responsable de asegurar que las emisiones de $\mathrm{CO}_{2}$ decrezcan en la medida indicada por Urgenda, y consecuentemente lo conminó a actuar para limitar el volumen de estas» (Rodríguez García, 2016: 7). La sentencia fue confirmada por el Tribunal de Apelación de La Haya, y en diciembre de 2019 la Suprema Corte de Holanda confirmó la sentencia.

Destacan dos cuestiones de esta sentencia: la ampliación de la legitimación activa y la defensa de derechos de las futuras generaciones. Sobre lo primero, el Estado holandés alegó que la ONG Urgenda no poseía legitimación activa para litigar ante el Estado en representación de las víctimas. En este punto, y por el contrario, el Tribunal de Apelación consideró que si las acciones en litigio por interés público caben ante el Tribunal Europeo de Derechos Humanos (TEDH) lo mismo ocurre en las jurisdicciones nacionales, por tanto, Urgenda sí poseía legitimación activa (Soro, 2019: 127).

Respecto de los derechos de futuras generaciones, pese a no contener reglas en el Código Civil holandés, el Tribunal acoge el argumento de la demandante para defender los derechos de futuras generaciones, ampliando la legitimación activa, recono- 
ciendo un interés transfronterizo y considerando a las futuras generaciones en el rol del Estado respecto al cambio climático (Soro, 2019: 128).

En el caso de la India existe un desarrollo progresivo, que se inicia en la década de los setenta, que busca hacer frente a los problemas ambientales del país causados por la contaminación, la creciente urbanización, la veloz industrialización que afectan el agua, la tierra y el aire. La Suprema Corte de la India ha desarrollado lo que se ha llamado giro populista desde la public interest litigation (Olivetti, 2008: 361).

El advenimiento del litigio de interés público (PIL) es uno de los componentes clave del enfoque del 'activismo judicial' que se atribuye al poder judicial superior de la India. [...] El litigio de interés público es un mecanismo de reparación permitido por el Honorable Tribunal Supremo y los Tribunales Superiores [...] para la aplicación de los derechos legales constitucionales y otros de cualquier persona o grupos de personas que, debido a su posición desventajosa, no pueden acudir a la corte en busca de alivio. Ha sido ampliamente utilizado como una herramienta eficaz para controlar los actos de degradación ambiental (Tomar y Varuni: 2017: 57; la traducción es nuestra, como todas las que siguen).

En el Tribunal Supremo indio:

La litigación en interés público sirve en la actualidad a una finalidad que trasciende la defensa de los derechos de los sectores más débiles de la sociedad, y que se utiliza para denunciar el mal funcionamiento de algunos servicios públicos, los efectos nocivos de industrias diversas y las injusticias que sufren grupos determinados de la sociedad (Sánchez González, S/N).

Parasan y Luthra señalan: «En la India, el activismo judicial ha sido fundamental para el progreso sociojurídico en diversas áreas y ha sido de particular relevancia en la protección de los derechos de las mujeres y del medio ambiente» (Pasaran y Luthra, 2018: 181). En este ámbito, afirman, emergen algunos nuevos conceptos de la Suprema Corte de la India,

Un nuevo entendimiento bajo el concepto de Public Trust Doctrine en el caso M.C. Meha v. Kamal Nath Ors. [...] Esta doctrina, originada en el derecho romano, entiende que los recursos naturales son mantenidos en fideicomiso para el Estado, para asegurar su uso beneficioso en las personas, así, el gobierno de la India es el administrador de esos recursos naturales [...] el aire, el agua, los bosques, los lagos, etc., ríos y vida silvestre y, por lo tanto, es responsable de su uso y protección adecuados (Pasaran y Luthra, 2018: 191; la traducción es nuestra).

Quisiera agregar una brevísima referencia al caso de China, donde también se evidencian tensiones entre protección del ambiente y economía. Zhuoxian Zhang agrega que gracias a las condenas a acusados en casos ambientales de interés público, 
ha sido posible accionar después en las jurisdicciones civiles «para desafiar a un gran poder local» (Zhang, 2018: 248; la traducción es nuestra).

En Latinoamérica, los jueces en Colombia también han desarrollado sentencias innovadoras a partir de los litigios de interés público medioambiental. La Sentencia T-622/16 del 10 de noviembre de 2016 dictada por la Corte Constitucional de Colombia en cuanto la ampliación de la legitimación activa señala que «ha flexibilizado las condiciones de procedibilidad de las tutelas promovidas para salvaguardar derechos fundamentales de las colectividades étnicamente diferenciadas».

Sobre el interés general (que consideramos en este caso equivalente al interés público), la sentencia afirma:

Solo a partir de una actitud de profundo respeto y humildad con la naturaleza, sus integrantes y su cultura es posible entrar a relacionarse con ellos en términos justos y equitativos, dejando de lado todo concepto que se limite a lo simplemente utilitario, económico o eficientista.

La sentencia reconoce al río Atrato, cuenca y afluentes, como sujeto de derecho para efectos de su «protección, conservación, mantenimiento y restauración a cargo del Estado y las comunidades étnicas».

En cuanto a medidas innovadoras, la Corte ordena a varios ministerios, universidades, organizaciones de la sociedad civil, nacionales e internacionales que diseñen planes de descontaminación de cuenca, afluentes y riveras del río Atrato y la recuperación de ecosistemas. La sentencia contempla medidas concretas y planes integrales de recuperación ${ }^{13} \mathrm{y}$ propone además un sistema de acompañamiento a cargo de la Procuraduría General de la Nación, la Defensoría del Pueblo y a la Contraloría General de la República, para que verificar la ejecución de las órdenes del Tribunal.

El litigio de interés público de corte experimentalista pone énfasis en medidas innovadoras, de transparencia y supervisión de cumplimiento de las decisiones. Contribuye, en palabras de Sabel, Simon y Mamberti, a la operatividad de derechos de interés público, y a concretar obligaciones que de otra manera terminan diluidas en el régimen de distribución de poderes y aporta al cumplimiento de las obligaciones establecidas en la ley (2018: 9 y 10). Desde esta perspectiva, la sentencia de la Tercera Sala de la Corte Suprema, en el caso Quinteros Puchuncaví desarrolla técnicas propias de las acciones de interés público en cuanto al tipo de medidas que ordena al poder ejecutivo. ${ }^{14}$

La ampliación de la legitimación activa y el conjunto de medidas que adoptan los jueces para reforzar la comparecencia en juicio y a la hora de resolver, se relaciona

13. Véase la Sentencia T-622/16 disponible en https://bit.ly/31asgtm.

14. Recurso de protección, Sentencia de la Corte Suprema, rol 5888-2019, deñ 25 de mayo de 2019, considerando $43 .{ }^{\circ}$. 
precisamente con la idea de interés público presente en los litigios ambientales. En este caso, el interés público adquiere consistencia y materialidad e impulsa nuevos criterios en la jurisprudencia, que también se promueven en el ámbito internacional para reforzar el acceso a la justicia. El interés público no es una mera referencia vacía de significado, al contrario, impulsa transformaciones.

El interés público - esta categoría volátil, flexible, que varía de contenido según el objeto que se considere propio de su dominio- ofrece una respuesta jurídica para abordar no solo la protección del ambiente, sino que también promueve una nueva aproximación a los litigios minero-ambientales que se producen en Chile.

\section{El interés público global medioambiental}

En la comunidad internacional resulta paradigmática la tensión entre los diagnósticos científicos alarmantes sobre el estado del medio ambiente global y la imposibilidad de generar respuestas a su degradación (ONU Medio Ambiente, 2019: 25). A partir de la comprensión del interés público global ambiental se construye el régimen jurídico internacional del medio ambiente, se incorporan nociones estratégicas como desarrollo sostenible, solidaridad intergeneracional, se refuerza la idea de los bienes comunes y se promueven reflexiones para que este interés se concrete en territorios como la Antártica. Sin embargo, estos aportes no logran concretar una agenda global eficiente de protección ambiental.

La complejidad del asunto se relaciona con la fragilidad del medio ambiente y la condición interconectada de los sistemas ecológicos que sostienen al planeta, que se han visto impactados por los patrones de la globalización.

Hay un creciente entendimiento público de que la degradación actual puede conducir a la pérdida de muchos de los tesoros patrimoniales más grandes de la humanidad y miles de especies (Cordonier, 2012: 848).

Cordonier sostiene que el derecho internacional puede jugar un rol en los problemas que identifica, tanto en su producción como su solución, porque junto con la aparición de una sociedad civil global, al mismo tiempo se desafía la idea de generar consensos planetarios para enfrentar los orígenes del problema y también las respuestas (Cordonier, 2012: 852).

Teruo Komori destaca que, en años recientes, buena parte del derecho internacional ha sido creado para proteger el interés de la comunidad global, incluidos los derechos de las futuras generaciones, a través de tratados multilaterales para la protección del medio ambiente (Komori, 2009: 1).

Como vemos, existe una identidad entre el interés público global y los litigios de interés público ambiental, la preocupación por las futuras generaciones, la solidari- 
dad intergeneracional, la dimensión transfronteriza de muchos problemas ambientales, subyacen y aportan luces a la idea de interés público en la minería.

\section{Los contenidos del interés público global ambiental}

No existe consenso respecto a qué cuestiones constituirían un asunto de interés global, pero es evidente la toma de conciencia sobre determinados problemas ambientales que, por su naturaleza, son globales tanto en sus orígenes difusos y por sus efectos generalizados, como ocurre con la contaminación del mar, pérdida de diversidad biológica, además de diversos fenómenos atmosféricos como lluvia ácida y el cambio climático (Juste Morales, 2015: 471).

Uno de los componentes del interés público global, desde el punto de vista de los actores, es la participación. La sociedad civil y las ONG son sujetos de la construcción del interés público global. A través de distintas formas proporcionan informes, seguimientos de compromisos, misiones de observación e investigación, difunden normas y promueven la participación (Rodríguez García, 2015: 239), como la que contiene el Acuerdo de Escazú, que no ha sido ratificado por el país pese a una intensa campaña de la sociedad civil en su favor.

En el derecho internacional convencional, para la determinación de aquello que es un asunto de interés global, se suele recurrir a los términos de los tratados, a los preámbulos y al carácter incuestionable sus normas. Afirma Rosario Huesa que el carácter más claramente definidor de lo que es un asunto de interés público global pude ser el objeto de protección de la norma, especialmente cuando ella se refiere a un bien común (Huesa, 2015).

\section{La idea de lo común}

Desde la perspectiva del interés público global, se aborda lo ambiental como un asunto asociado a lo común, que pertenece y afecta a todas las personas y que requiere de medidas y respuestas coordinadas. Este interés da origen al régimen internacional del medio ambiente, que contiene principios y criterios, muchos de ellos con incidencia concreta en los ordenamientos internos, como el derecho a un medio ambiente sano (Estocolmo, 1972), al desarrollo sostenible (Informe Brundtland, 1987), principios preventivo y precautorio (Cumbre de la Tierra Río, 1992 y Conferencia de Desarrollo Sostenible, Río +20, 2012); Acuerdo de París sobre Cambio Climático (2016); Opinión consultiva número 23 de la Corte IDH (2017), solo por mencionar algunos. Cordonier afirma:

El desarrollo sostenible como un objetivo de «interés público» común y global, afirmado en innumerables ocasiones por la comunidad internacional, puede pro- 
porcionar un «concepto puente» útil en casos de intersección de regímenes (Cordonier, 2009: 226; la traducción es nuestra).

\section{El interés público global en territorios: la Antártica}

Uno de los territorios en torno a los cuales se está reflexionando desde la perspectiva del interés público es el patrimonio común de la Antártica. Sobre esta materia, Wolfrum afirma:

Una aceptación externa del régimen jurídico antártico depende de una mayor protección del medio ambiente como interés comunitario, la transparencia de las decisiones tomadas por las Partes con respecto a la Antártida y la apertura del régimen para la adhesión. [...] En los últimos años, el régimen jurídico de la Antártida ha sufrido bastantes modificaciones a este respecto. Sin embargo, como se observará, hay indicios de que el péndulo a favor de un régimen jurídico antártico abierto está retrocediendo (Wolfrum, 2017: 145).

Wolfrum identifica diversos modelos en la discusión en torno al territorio Antártico. Uno de esos enfoques se relaciona con la soberanía de los Estados, que está más motivado por cuestiones políticas y legales y ha sido la discusión más frecuente sobre el territorio antártico.

Otros enfoques están más relacionados con la idea de la protección del patrimonio común que contiene la Antártica:

refiriéndose al hecho de que el fondo marino profundo y sus recursos, así como la luna y sus recursos han sido declarados patrimonio común de la humanidad, abogan por la extensión de ese principio a la Antártida o al menos a los recursos minerales y su administración por una autoridad internacional similar a la Autoridad de los Fondos Marinos (Wolfrum, 2017: 144).

Acá el interés público global se comprende como una razón para crear, modificar o transformar la gestión de ciertos territorios por su valor, hacia un régimen basado en asegurar el interés público global a través de la protección y conservación de esos territorios.

A propósito del interés público global en ciertos territorios, se ha acuñado otra noción asociada, la idea de los global public goods (Hey, 2012). Hey identifica el origen de esta noción en el trabajo de economistas del Programa de Naciones Unidas para el Desarrollo, aunque también es desarrollada por el Banco Mundial. Respecto a esta teoría, como es evidente, se puede anticipar que ha generado diferencias y tensiones, especialmente en los países en vías de desarrollo porque los global public goods conceptualizan e identifican diversos recursos naturales que se encuentran en áreas que 
se consideran de interés ambiental, y muchos de ellos se encuentran en territorios de países menos desarrollados.

\section{El interés público global y las inversiones}

A propósito del interés público en el ámbito internacional y de los tratados de inversión, Yotova agrega:

Arbitrar el interés público puede caracterizarse como una nueva frontera del derecho internacional de inversiones dado el aumento detectable de los desafíos planteados por los inversores contra las medidas regulatorias adoptadas por los estados para proteger el interés público (Yotova, 2016: 247).

Yotova alerta sobre la creciente tendencia de cláusulas expresas que buscan preservar las competencias de los Estados para establecer regulaciones que protejan el interés público.

La tendencia también se refleja en el Informe Mundial sobre Inversiones de la Conferencia de las Naciones Unidas sobre Comercio y Desarrollo (UNCTAD) de 2015, en el que se observa que de los dieciocho tratados de inversión celebrados en 2014, catorce contenían una cláusula referida al interés público, incluida la protección salud, seguridad y medio ambiente (Yotova, 2016: 247).

El capitalismo global y la debilidad del interés público llevan a Christopher Newdick a definir al interés público como un sleepwalking into disaster (Newdick, 2016: 23).

En síntesis, hemos podido ver cómo en el mundo contemporáneo se ha llenado de significado ambiental la idea del interés público. Lo nuevo del concepto proviene de un hecho incuestionable, la degradación del ambiente y la conflictividad ambiental. Los esfuerzos de la comunidad internacional, a veces vanos para proteger el ambiente, el aire, la diversidad biológica y zonas singulares como la Antártica, son una consecuencia del interés público que todos estos asuntos representan para la comunidad internacional.

El estudio del interés público en la minería nos lleva a reflexionar sobre su pobre significado en la Constitución y la manera en que se ha comprendido la actividad minera en Chile, más gobernada desde lo privado que desde lo público.

El uso de conceptos como el que hemos estudiado debiera llevarnos a una reflexión profunda respecto al proceso constituyente que se inicia y, sobre todo, a valorar y anticipar las consecuencias de los términos y compromisos que la futura Constitución consagre en el ámbito ambiental y económico. 


\section{Conclusiones}

La limitada interpretación del interés público en la minería, reducido al interés económico y fiscal débil, evidencia un vacío constitucional, una falta de atención hacia lo público, hacia los impactos que la actividad económica a gran escala puede tener en los territorios.

La Constitución de 1980 ha resuelto la cuestión de la propiedad de los recursos naturales, pero no la forma en que esa actividad debe desarrollarse. La restrictiva interpretación del interés público, asociado al pago de patente o desarrollo efectivo de la actividad minera, es una interpretación retrasada, incoherente con los signos ambientales y los impactos de la minería en el territorio.

Pese a las críticas que se pueda plantear a la comprensión vital de los principios que contiene toda Constitución, durante la vigencia de la Constitución de 1980 siempre han estado presentes el Estado subsidiario y los énfasis en la protección de la libertad de empresa y el derecho de propiedad. Sin embargo, otras nociones presentes en su texto desde el origen no han tenido impacto. Quizá la causa es, entre otras, una pésima técnica legislativa, porque el interés público aparece en una extensa disposición donde se trata el derecho de propiedad.

La Constitución de 1980 ha producido un país, un Estado poco atento a lo público, temeroso de ejercer su rol como regulador, retraído en la protección sólida de los derechos sociales.

Desde la perspectiva del proceso constituyente, sin embargo, es interesante explorar cómo la idea de interés público aporta a la comprensión de lo ambiental en la Constitución, particularmente de la minería. Es una noción valiosa para que un ámbito tan estratégico tenga directrices y principios rectores mucho más allá de la regulación del derecho de propiedad.

La revitalización del interés público, a propósito del medio ambiente, lo ha convertido en una noción preferente a la hora de abordar los problemas comunes/globales. El gobierno de lo común, articulado a partir del interés público, encuentra un terreno fértil para el surgimiento de nuevos criterios que puedan hacerse cargo de los enormes desafíos que tenemos.

Las categorías jurídicas clásicas del derecho tienen dificultades para hacerse cargo de la protección del medio ambiente y la naturaleza. Las nuevas dimensiones del interés público abren un camino para el mejor tratamiento de lo ambiental desde el punto de vista jurídico. Esta noción clásica conserva su actualidad por ser dúctil.

El interés público alude al interés de la colectividad completa, prevalece frente a intereses específicos. El interés público que debe satisfacer el titular de la concesión minera le obligan a desarrollar su actividad considerando no solo el interés privado, también el público, por tanto, deberá considerar los efectos ambientales y ecosistémicos de su industria en un corto y largo plazo. 
Las acciones de litigio por interés público medioambiental demuestran efectos concretos derivados del interés público, que motiva respuestas extraordinarias para asegurar el acceso a la justicia y la restauración. La ampliación de la legitimación activa, las nuevas medidas de supervisión de cumplimiento de sentencias y las medidas de hacer, son consecuencia del interés público presente en esta clase de litigios. Con ello se concretan los derechos de acceso a la justicia ambiental.

Desde la perspectiva del interés público global ambiental se ha construido el régimen internacional del medio ambiente. A pesar de sus debilidades, el derecho internacional ha hecho aportes notables al tratamiento jurídico del ambiente, especialmente en la formulación de principios (Jaria-Manzano, 2019).

Sea en la presente o futura Constitución, se debe reconstruir la noción de interés público en el ámbito constitucional. En el interés público ambiental existe un potencial transformador que merece ser explorado, la explotación de los recursos naturales exige una mirada más allá de los beneficios económicos que esta actividad tan estratégica reporta al país. El titular de una concesión minera debe satisfacer ese interés público que justifica su otorgamiento y considerar los impactos de su actividad en el ambiente, debe prevenir, reparar y restaurar cada vez que sea necesario.

\section{Referencias}

Alexy, Robert (2004). Epílogo a la Teoría de los Derechos Fundamentales. Madrid: Centro de Estudios Constitucionales.

BARNES, Javier (2012) «El sujeto privado en la Constitución económica: de la vertiente de la defensa de los derechos y libertades a la dimensión activa de los actores privados en cuanto protagonistas y corresponsables de la vida económica». En La Constitución Económica. Asociación de Letrados del Tribunal Constitucional, 33. Madrid: Centro de Estudios Políticos y Constitucionales.

Centro de Análisis de Políticas Públicas, Universidad de Chile (2018). Informe País. Estado del Medio Ambiente en Chile 2018. Santiago: Universidad de Chile. Disponible en https://bit.ly/3ywSgLE.

CePAl (2018). «Acceso a la información, la participación y la justicia en asuntos ambientales en América Latina y el Caribe Hacia el logro de la Agenda 2030 para el Desarrollo Sostenible». Disponible en https://bit.ly/3F3Ko8C.

Claussen, Carlos (1988). "Análisis del sistema de amparo de la propiedad minera». Revista Chilena de Derecho, 15 (2/3): 235-254. Disponible en https://bit.ly/34dItiR.

Cordonier, Marie Claire (2009). «Effective implementation of intersecting public international regimes: Environmental, development and trade law». En Komori Teruo y Karel Wellens (editores), Public interest rules of international law: Towards effective implementation. Londres: Ashgate Publishing.

-. (2012). «Justice sustainnability and solidary for future generations». En Michel 
Morin, Marie-Claire Cordonier Segger, Fabien Gélinas y Markus Gehring (editores), Responsibility, fraternity and sustainability in law. In memory of the honourable Charles Doherty Gonthier. Ontairo: Lexis Nexis.

Cornago, Noé (2015). «De la filosofía política a la gobernanza global: Un acercamiento crítico a la noción de interés público global». En Noé Bouza y otros (directores), La gobernanza del interés público global. Madrid: Tecnos.

Covarrubias, Ignacio (2012a). «Las falencias del test de interés público como instrumento de ponderación entre el acceso a la información pública y la vida privada». Revista de Derecho (Pontificia Universidad Católica de Valparaíso), 38: 499-541. Disponible en https://bit.ly/3mJKQQx.

-. (2012b). «El interés público como convergencia entre la libertad de expresión, el acceso a la información y el derecho a la vida privada». Revista de Derecho (Pontificia Universidad Católica de Valparaíso), 44: 267-306. Disponible en https://bit. ly/3sKCqfC.

Croley, P. Steven (2004). Regulation and public interest. Princeton University Press. Douglass, Bruce (1980). «The Common Good and the Public Interest». Political Theory, 8 (1): 103-117.

Elliot Mark, Jason Varuhas y Shona Wilson (editores) (2018). The unity of public law? Doctrinal, theoretical and comparative perspectives. Oxford, Portland Oregon: Hart Publishing.

Environmental UN (2019). «Environmental Rule of Law. First Global Report. Summary». Disponible en https://bit.ly/33BCKTB.

EsPinozA, Carlos (2007). «Izquierda populista, nacionalismo de recursos naturales y la geopolítica en los Andes». Revista Comentario Internacional, 7: 126-144.

EY (2018). «Análisis comparado de carga tributaria en algunos países mineros, Estudio encargado por Consejo Minero A.G.». Disponible en https://bit.ly/3EoEimG.

FigueroA, Rodolfo (2016). «Inviolabilidad de correos electrónicos». Anuario de Derecho Público UDP. Disponible en https://bit.ly/3scc $7 \mathrm{Pm}$.

Feintuck, Mike (2004). «How is the public interest determined?». En Mike Feintuck, The public interest in regulation. Oxford: Oxford University Press.

Friedrich J. CARl (1962). El INTERÉS PÚblico. MÉXico: Editorial Roble.

FolCHI, Mauricio (2001). «La insustentabilidad de la industria del cobre en Chile: los hornos y los bosques durante el siglo XIX». Revista Mapocho, 49.

-. (2009). «Política, ambiente y la insustentabilidad de la minería en Chile». En Jürgen Schuldt y otros, Extractivismo, política y sociedad. Quito: Centro Latinoamericano de Ecología Social. Consultado el 26 de octubre de 2021. Disponible en https://bit.ly/3qokVFa.

Galdámez Zelada, Liliana (2017). «Medio ambiente, Constitución y tratados en Chile». Boletín Mexicano de Derecho Comparado, 50 (148): 113-144. Disponible en https://bit.ly/3eBJBiz. 
-. (2020). «El medio ambiente en la jurisprudencia del Tribunal Constitucional de Chile». Revista de la Facultad de Derecho, 48: e107. DOI: 10.22187/rfd2020n48a7.

Galdámez Zelada, Liliana y Salvador Millaleo Hernández (2020). «La naturaleza en la Constitución: visiones indígenas y propuestas ante la crisis». Acta Bioethi-

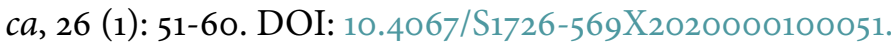

Gargarella, Roberto (2018). «Sobre el nuevo constitucionalismo latinoamericano». Revista Uruguaya de Ciencia Política, 27 (1): 109-129. DOI: 10.26851/rucp.27.5.

Geuss, Raymond (2003). Public goods, private goods. Princeton: Paperback.

Grez Toso, Sergio (2017). «Procesos constituyentes de las élites chilenas». En Centro de Estudios Latinoamericanos "Justo Arosemena" Panamá, Tareas, núm. 155, eneroabril, 2017: 21-33. Disponible en https://bit.ly/3qCLHUh.

GruniNG, James E. (2009). «Paradigms of public relatinos in an age of digitalization». The Public Relations Resource Centre, 6 (2): 1-19. Disponible en https://www. researchgate.net/publication/46280145.

Hey, Ellen (2012). «Conceptualizing global natural resources: Global public goods theory and international legal concepts». En Holger Hestermeyer y otros, Coexistence, Cooperation, and Solidarit. Leiden Boston: Martinus Nijhoff Publishers.

Huesa, Rosario (2015). «La protección del interés público global: una nueva dimensión para las normas y obligaciones internacionales». En Nuria Bouza, Caterina García y Ángel J. Rodrigo (directores) y Pablo Pareja (coord.), La gobernanza del interés público global. Madrid: Tecnos.

Jaria-Manzano, Jordi (2019). «Los principios del derecho ambiental: Concreciones, insuficiencias y reconstrucción». Ius et Praxis, 25 (2): 403-432. DOI: 10.4067/ So718-00122019000200403.

Juste Morales, José (2015). «La gobernanza del interés público global. El papel de los actores no estatales en la protección del interés público global». En Nuria Bouza, Caterina García y Ángel J. Rodrigo (directores) y Pablo Pareja (coord.), La gobernanza del interés público global. Madrid: Tecnos.

Komori, Teruo (2009). "Changing Character of International law». En, Komori Teruo y Karel Wellens (editores), Public interest rules of international law: Towards effective implementation. Londres: Ashgate Publishing.

Lewis, Carol W. (2006). «In pursuit of the public interest». Public Administration Review, 66 (5): 694-701.

López CALera, Nicolás (2010). «El interés público entre la ideología y el derecho». Anales de la Cátedra Francisco Suárez, 44: 123-148. Disponible en https://bit. ly/3HmzKZU.

Lovera, Domingo (2006). «El interés público como estándar. Libertad de expresión y vida privada». Publicaciones Centro de Derechos Humanos Universidad Diego Portales. Disponible en https://bit.ly/3zacVpp. 
MeLler, Patricio (2003). «El cobre chileno y la política minera». Santiago, Serie Estudios Socio/Económicos núm. 14, Cieplan. Disponible en https://bit.ly/30ZYY9Q.

Newdick, Christopher (2016). «Global capitalism and the crisis oh the public interest- sleepwalking into disaster». En Susan Breau y Samuel Katja, Research Handbook on Desasters and International Law. Cheltenham: Edward Elgar.

OCDE (2018). «Estudios Económicos de la OCDE». Disponible en https://bit. $\mathrm{ly} / 3 \mathrm{mIYOO} 2$.

OCDE y Cepal (2016). «Evaluaciones del desempeño ambiental. Chile, 2016». Santiago, Naciones Unidas. Disponible en https://bit.ly/3E3FDZP.

Olivetti, Marco (2008). «El Tribunal Supremo de la India como órgano de justicia Constitucional. Apuntes introductorios». Estudios en homenaje a Héctor Fix-Zamudio. Biblioteca Jurídica Virtual del Instituto de Investigaciones Jurídicas de la UNAM. Disponible en https://bit.ly/3pFjqon.

ONU Medio Ambiente (2019). GO6 Perspectivas del Medio Ambiente Mundial. Planeta sano, personas sanas. Nueva York: ONU. Disponible en https://bit.ly/32MZIGG.

Pasaran, Mohan y Luthra Sidhatrh (2018). «Public Interest Litigation. And effective Tool for Biodiversity Conservation». En Tandon Usha, Pasaran Mohan, Luthra Sidharth (eds.), Biodiversity Law, Policy and Governance. Londres: Routledge.

Peña Torres, Marisol y Cecilia Rosales Rigol (2010). «El interés público en el constitucionalismo postmoderno». Revista de Derecho (Pontificia Universidad Católica de Valparaíso), 22: 483-502. Disponible en https://bit.ly/3EE3cc4.

Rodríguez García, Noel (2016). «Responsabilidad del Estado y cambio climático: El caso Urgenda c. Países Bajos». Revista Catalana de Derecho Ambiental, 721-38. Disponible en https://bit.ly/3Fiunyk.

Roxbee Cox, J. W. (1973). «The appeal to the public interest». British Journal of Political Science, 3 (2): 229-241.

Ruiz Tagle, Pablo (2018). «La propiedad en Chile y sus dilemas». Revista de Derecho (Pontificia Universidad Católica de Valparaíso), 51: 199-230. Disponible en https:// bit.ly/31abviq.

SABEL, Charles, Simon, William y Mamberti, Maria (2018). «Derechos de desestabilización: el triunfo del Litigio de Interés Público». Revista De Interés Público, 2: 9-91. Disponible en https://bit.ly/33X16XV.

Salazar Ugarte, Pedro (2013). «El nuevo constitucionalismo latinoamericano una perspectiva crítica». En Constitucionalismo contemporáneo. Homenaje a Jorge Carpizo. México: UNAM. Disponible en https://bit.ly/3HojlnD.

SÁnchez González, Santiago (2019). «La Constitución de la India». Disponible en https://bit.ly/3pGMSTI.

Soro, Blanca (2019). «Responsabilidad pública, vulnerabilidad y litigios climáticos». Revista Aragonesa de Administración Pública, 54: 57-140. Disponible en https://bit. ly/3pDpwxX. 
Vergara Blanco, Alejandro (1989). «Derechos mineros en Chile», Revista Chilena de Derecho, 16 (1): 43-65. Disponible en https://www.jstor.org/stable/i40076703.

VoIGt, Christina y Makuch Zen (2018). Courts and the Environment. Cheltenham UK, Northampton, MA, USA: Edward Elgar Publishing.

von Bogdandy, Armin (2015). «Ius Constitutionale Commune en América Latina: una mirada a un constitucionalismo transformador», Revista Derecho del Estado, 34: 3-50. DOI: 10.18601/01229893.n34.01.

TAPIA VALDÉs, Jorge (2003). «Descentralización y subsidiaridad en la época de la globalización». Revista Estudios Constitucionales, 1 (1): 99-111. Disponible en https:// bit.ly/3FFs2JK.

Tomar, Aditiya y Yadav Varuni (2017). «Good Governance and Human Rights in Developing Nations». En Komal Vig y Suhas Hosamani, Role of Public Interest Litigation in Environmental Jurisprudence in India. Nueva Delhi, Mumbai, India: Bharti Publications.

Tomic, Radomiro (1986). «La política minera chilena». Documento presentado el día 11 de octubre de 1984 en el Seminario Formación Democrática organizado por el Centro de Estudios Públicos. Disponible en https://bit.ly/3p2xQY8.

WOLFRUM, Rüdiger (2017). «Common interest and common heritage in Antarctica». En Klaus Dodds, Alan Hemmings y Peder Roberts, Handbook on the Politics of Antarctica. Cheltenham: Edward Elgar.

Yotova, Rumiana (2016). «Arbitrating the Public Interest». En Proceedings of the 11oth Annual Meeting. Charting New Frontiers in International Law, Washington: American Society of International Law.

ZhANG, Zhuoxian, (2018). "What Chinese courts could learn from USA: The approach of public interest litigation under the new China Environmental Protection Law». En Christina Voigt y Makuch Zen, Courts and the Environment. Cheltenham: Edward Elgar.

Zagrebelsky, Gustavo (2011). El derecho dúctil, ley, derechos justicia. Madrid: Trotta. Zuñiga Urbina, Francisco (2005). «Constitución y Dominio Público (Dominio Público de Minas y Aguas Terrestres». Ius et Praxis, 11 (2): 65-101. Disponible en https://bit.ly/32tPtrj.

\section{Agradecimientos}

Este trabajo se desarrolla en el marco de una estancia de investigación adjudicada en concurso interno de la Universidad de Chile, en el Max Planck Institute for Comparative Public Law and International Law, de Heidelberg, Proyecto de Internacionalización UCH-1566. 


\section{Sobre la autora}

Liliana Galdámez Zelada es doctora en Derecho por la Universidad de Valladolid y licenciada en Ciencias Jurídicas y Sociales por la Universidad de Chile. Profesora en la Facultad de Derecho de la Universidad de Chile. Su correo electrónico es lgaldamez@derecho.uchile.cl. (D) https://orcid.org/0000-0003-2889-1629. 
La Revista de Derecho Ambiental, del Centro de Derecho Ambiental de la Facultad de Derecho de la Universidad de Chile, es un espacio de exposición y análisis en el plano académico del derecho ambiental. Su contenido se presenta a través de doctrina, jurisprudencia y recensiones, y aborda diversas materias relacionadas con la gestión, institucionalidad y herramientas de protección ambiental y desarrollo sustentable. Se presentan artículos de diferentes autores y autoras en los que se analizan y abordan casos y temas jurídico-ambientales de creciente interés y actualidad.

\author{
DIRECTORA \\ Valentina Durán Medina \\ EDITORES \\ Jorge Ossandón Rosales \\ y Antonio Pulgar Martínez \\ SITIO WEB \\ revistaderechoambiental.uchile.cl \\ CORREO ELECTRÓNICO \\ revistada@derecho.uchile.cl \\ LICENCIA DE ESTE ARTÍ́CULO \\ Creative Commons Atribución Compartir Igual 4.o Internacional
}

La edición de textos, el diseño editorial

y la conversión a formatos electrónicos de este artículo

estuvieron a cargo de Tipográfica

(www.tipografica.io) 